\title{
A Review on John Snow's (1813-1858 CE) Contributions to the Epidemiology and Anesthesiology
}

Samad EJ Golzari ${ }^{{ }^{*}}$, Zahid Hussain Khan ${ }^{2}$, Ali Dabbagh ${ }^{3}$, Hadiseh Kavandi ${ }^{4}$, Ata Mahmoodpoor ${ }^{5}$, Babak Sabermarouf ${ }^{6}$, Hassan Soleimanpour ${ }^{7}$, Kazem Khodadoust $^{8}$, Behnam Dalfardi ${ }^{9}$, Mojtaba Heydari ${ }^{10}$, Kamyar $^{2}$ Ghabili $^{11}$

1. Medical Philosophy and History Research Center, Tabriz University of Medical Sciences, Tabriz, Iran

2. Department of Anesthesiology and Intensive Care, Imam Khomeini Medical Center, Tehran University of Medical Sciences, Tehran, Iran

3. Anesthesiology Research Center, Shahid Beheshti University of Medical Sciences, Tehran, Iran

4. Tabriz University of Medical Sciences, Tabriz, Iran

5. Cardiovascular Research Center, Tabriz University of Medical Sciences, Tabriz, Iran

6. Neurosciences Research Center (NSRC), Tabriz University of Medical Sciences, Tabriz, Iran

7. Road Traffic Injury Research Center, Tabriz University of Medical Sciences, Tabriz, Iran

8. Department of History of Medical Sciences, Faculty of Traditional Medicine, Tabriz University of Medical Sciences, Tabriz, Iran

9. Research Office for the History of Persian Medicine, Shiraz University of Medical Sciences, Shiraz, Iran

10. Research Center for Traditional Medicine and History of Medicine, Shiraz University of Medical Sciences, Shiraz, Iran

11. Tuberculosis and Lung Disease Research Center, Tabriz University of Medical Sciences, Tabriz, Iran

"In riding his hobby very hard, he has fallen down through a gully hole and has never since been able to get out again"

"Has he any facts to show in proof? No!"*

* From an Editorial on John Snow's theories published in the Lancet in 1855

\section{Biography}

John Snow, the famous physician, epidemiologist and anesthetist, was born on March 15th, 1813 in York, England (Image 1). He was the eldest of nine children born to William and Frances Snow in their North Street home. His first 12 years of life were spent in a poor and unsanitary area in Michaelgate. River
Ouse, which provided the drinking water for the people and often contaminated with excreta, was in the vicinity of his home. This exposed him and his family to the danger of flooding and contamination with excrements of drinking water (1).

After financial status of his father improved, they moved to a more wholesome area which was appropriate for the children's education. When he was 14, he was apprenticed to William Hardcastle, a surgeon in Newcastle upon Tyne School of Medicine. Later, he attended in lectures and visited the different wards of the local infirmary (2).

His apprenticeship was finished in 1833. Between 1833 and 1836 Snow worked as an assistant to a colliery surgeon. He returned to

\section{Corresponding author:}

Samad EJ Golzari, MD

Medical Philosophy and History Research Center, Tabriz University of Medical Sciences, Tabriz, Iran

E-mail: dr.golzari@hotmail.com Tel: +989141151894

Receive date: 2015-06-01| Accept date: 2015-06-15| Publish date: 2015-08-04

DOI: 10.7575/aiac.abcmed.15.03.04.03

\section{Al}




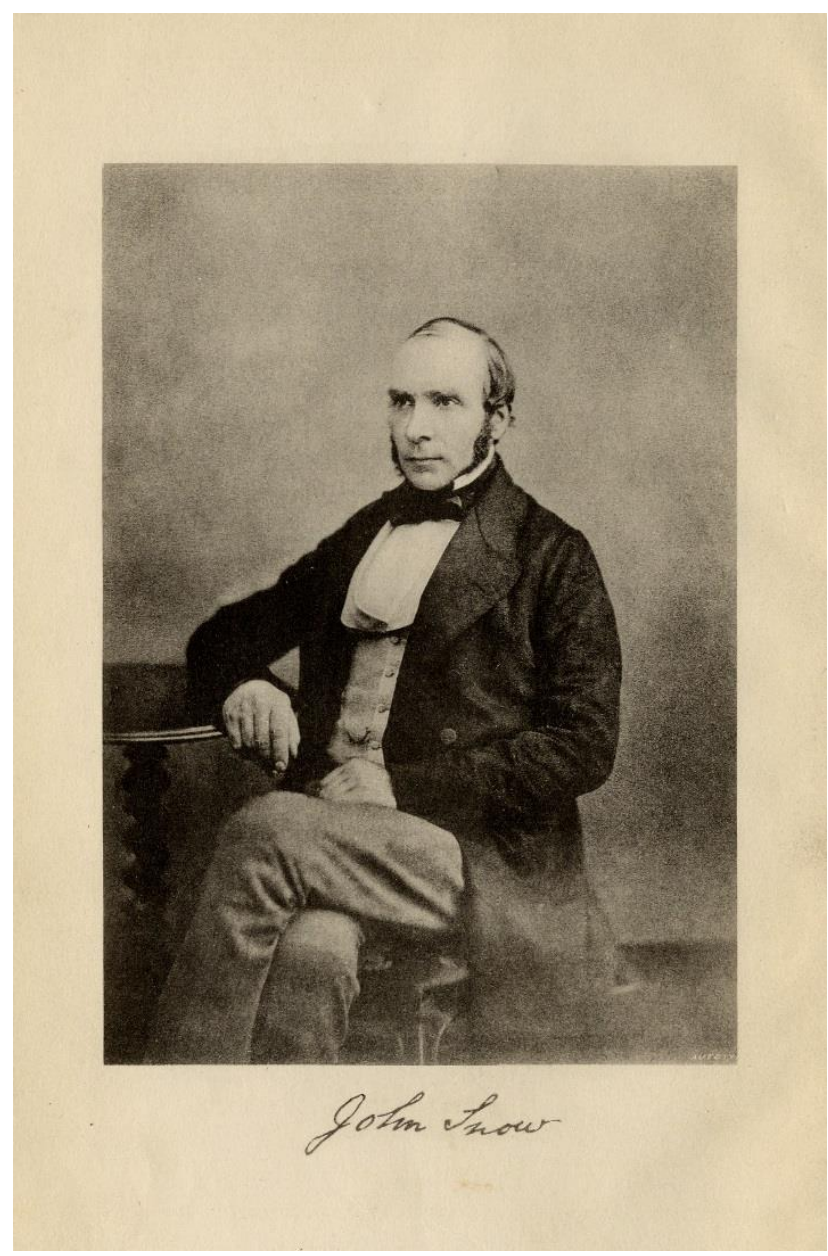

Image 1: John Snow (1813-1858 CE) image published with the permission of Library \& Archives Service, London School of Hygiene \& Tropical Medicine

London after completing his education to get a London degree and became a student in the Royal College of Surgeons and began working at the Westminster Hospital. Snow finished his education in 1844. Then he was elected as the chancellor of the London Medical Society. Snow suffered a stroke while working in his London office on June 10th, 1858. He was 45 years old at the time. This valuable and memorable researcher and scientist died in London on June 16th, 1858 aged 45 years from a stroke. He was buried in Brompton Cemetery (3). Many books, papers, and letters to journals on various topics such as rickets, chest deformities, the circulation of the blood, lead poisoning, and scarlet fever have been written by Snow during his short life (4).

\section{John Snow's Contributions to the Epidemiology}

Certainly, John Snow played an essential role in the advancement of epidemiology. He developed a novel epidemiological approach through consideration of different cholera incidence according to sources of household water supply in different areas (5).

In 1832, he first confronted with cholera, which was observed nearby a village, Killingworth (6).

Snow, a 19-year-old surgeon's apprentice at the time, was sent off alone to help the suffered people. He was motivated by that event and became interested in that field. In his writings on cholera, Snow expressed a hypothesis about disease transmission. He presumed the contamination of the water with the evacuations of cholera patients as the cause of dreadful outbreak of cholera in St James's parish like the Broad Street pump. (7)

This confidence of his seems reasonable, especially in hindsight, but it does not mean that his logic was airtight. In showing the significance of "offensive effluvia", another well-known theory to explain how cholera spread, he mentioned that "many places where offensive effluvia are very abundant have been visited very lightly by cholera, whilst the comparatively open and cleanly districts of Kennington and Clapham have suffered severely. A much closer connection would be found to exist between offensive effluvia and the itch than between these effluvia and cholera if there were any inquiry; but because of the popularity of itch, we definitely know that this connection is not one of cause and effect." (8) 
He advised personal hygiene and hand disinfection as the way to prevent the disease almost 160 years ago. (9) He presented the theory of contagion about cholera. In his theory he noted that household water sources would have to be kept separate from drains, cesspools, and sewers to stop transmission. His exact fieldwork and two well-known maps certified his theory when cholera observed in London 6 years later. His theory resulted in stopping the disease transmission. (10)

However, the birth of modern epidemiology is attributed to Snow who analyzed the cholera epidemic in 1854 (11).

In order to solve the problem, Snow was inspired by the facts that different infection rates were observed among different groups, such as brewery workers and washerwomen and the lady in West Hampstead, according to their amount of water consumption and its source (12).

In his point of view, additional funding should be allocated to cholera research because it was a public health priority. Snow requested an interview with the Board of Governors of St James Parish, who were notified of etiological factors and transmission route and commanded to remove the handle from the Broad Street pump (13).

He had treated cholera patients in the outbreak of 1831 as a young apprentice but he wrote nothing until 1849. Snow declared "On the Mode of Communication of Cholera", which was first published in 1849, during the world's second cholera pandemic, that cholera is a disease of gastrointestinal system. It was contagious and transmitted through the oralfecal route, mainly through contaminated drinking water. Shock and death occurred due to massive fluid loss and dehydration (13).

There was a belief that epidemic diseases such as cholera spread through gases emanating from the remains of animals and plants. Snow knew from his anaesthesia work that this theory was impossible. He confirmed his argument and provided sufficient evidence to the parliamentary in 1855 (14).

Snow discovered that the cholera toxin had to be a living organism capable of reproduction and 24-hour incubation period is the time required for replication of the organism. Thirty years after his statements Robert Koch's formulation of germ theory was propounded (15).

Snow was the first scientist that propounded the oral-fecal mode of transmission and explained epidemiological features of the disease.

A great experience that made him famous was to satisfy authorities to remove the well's pump handle in Broad Street, Soho, in 1854 (5).

Snow compared the epidemiology of cholera and numbers of victims between two outbreaks of cholera in 1848-49 and 1854-55. In 1848-49, water supplies of the Lambeth and the Southwark and Vauxhall water companies were prepared from Thames which was a place for discharge of London sewers. In 1854-55, the Lambeth water company had changed its source of water supply. After Lambeth's move, mortality and morbidity rates were significantly lower in people whose water was supplied by Lambeth Water Company in contrast to the people who supplied by the Southwark and Vauxhall water companies. Snow published these results in the second edition of On the Mode of Communication of Cholera with greater emphasis on the contaminated water transmission (12).

One of the striking features of Snow was that he used compilation of clinical observations, laboratory experiments and population-based information in both his anesthesia and cholera researches. Whereas other researchers mainly focused on predisposing factors that enhanced 


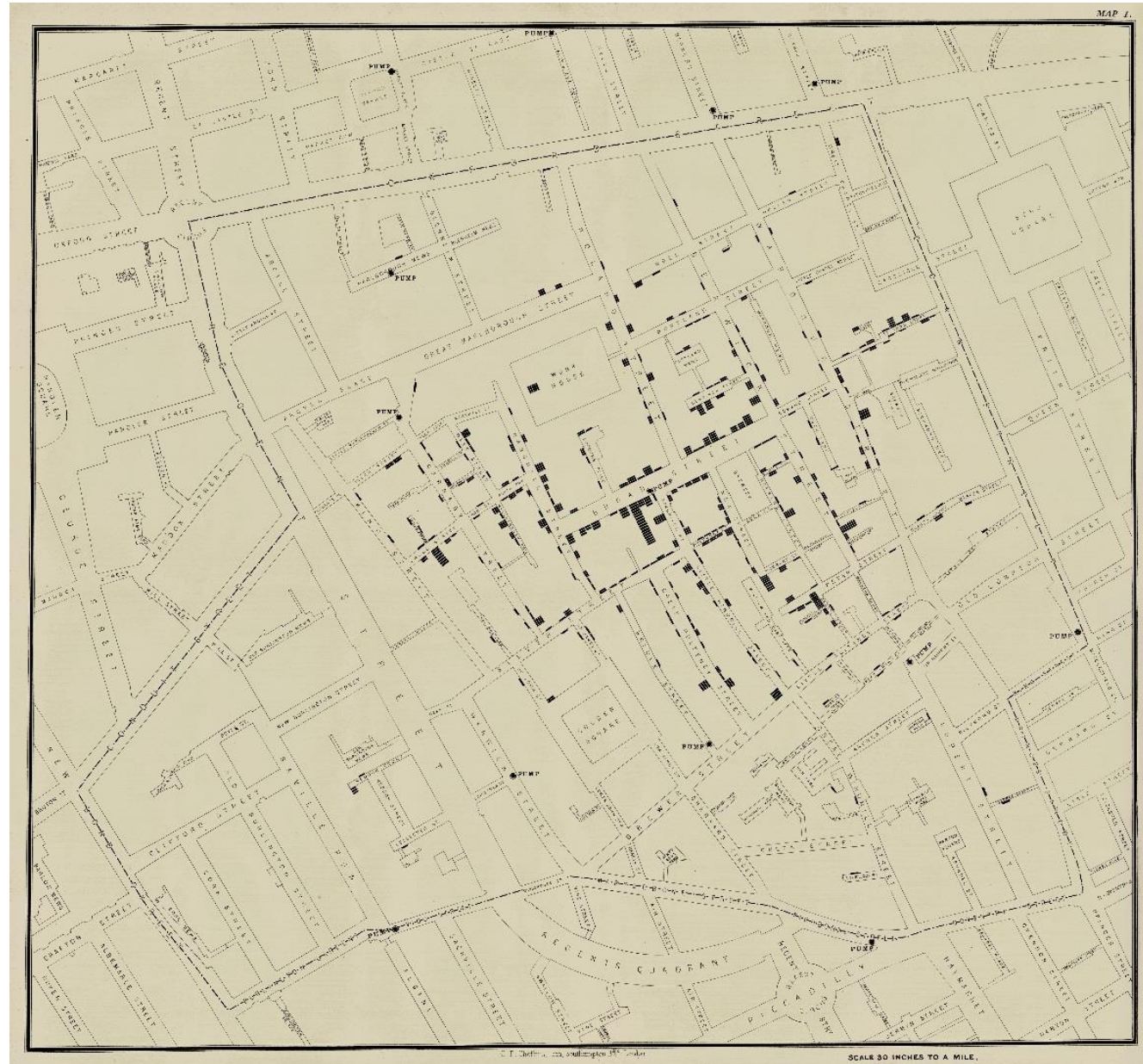

Image 2: Map John Snow showing the cholera cases in Soho in the London epidemic of 1854, from On the Mode of the Communication of Cholera, 1855. Published with the permission of Library \& Archives Service, London School of Hygiene \& Tropical Medicine

susceptibility to cholera, his research was based on the method of transmission of cholera and the subject of both of his books were devoted to modes of transmission of the disease (13).

He drew a map to show distribution of affected people. In the plan, the cross-hatch indicates St Luke's Church and the black lines showed deaths. In this map, higher rate of disease was observed in people who used Broad Street pump than other pumps (Image 2) (13).

Fifty-eight percent of the people who were supplied by pump water developed cholera in comparison with $7 \%$ among the people who used other source of water.
An engineering survey was organized in order to substantiate Snow's view about role of contaminated water in spread of cholera. The surveyors found the earth between the pump and place of cesspool drain wet so they stated there was a possibility of leakage from the cesspool to the pump shaft. So, Snow's remarks were fully confirmed.

Although his contributions to the science are immense, John Snow and his scientific theories were long ignored by the academia of the time. In 1855, an editorial was published on John Snow's theories in the Lancet in which his theories were described as follows: 
"In riding his hobby very hard, he has fallen down through a gully hole and has never since been able to get out again" and "Has he any facts to show in proof? No!"

Now after almost 200 hundred years, everyone is aware of his immense contributions to the different fields of the science. In 2013, the editors of the Lancet published an editorial on the commemoration of this prominent scientist and apologized for not recognizing his remarkable achievements in the field of epidemiology and his visionary work in deducing the mode of transmission of epidemic cholera.

Previously Snow had told members of parliament that the foul smells from processes such as tanning and soap boiling were not capable of producing acute fever or epidemic disease in an individual. Snow was accused of unscientific thinking by Wakley who incensed at what he saw as an attempt to block important public health reforms (17).

\section{John Snow's Contributions to the Anesthesiology}

When he was a medical student, Snow considered acute gastrointestinal symptoms among students who had exposure to arsenite of potash which was used as a preservative agent in the preservation of cadavers. He revealed that arsenic was released into the air when preservative was exposed to decaying tissue in a long time. This work on an inhaled poison was a beginning for his further studies in the field of anesthetics. He was evaluating respiration and asphyxia during the first use of ether in surgery in Britain, 1846 (18).

Later in 1847, John Snow published On the Inhalation of the Vapour of Ether in Surgical Operations, after a year of observation of the use of ether for dental extraction in England for the first time. He explained the basic elements of proper anesthesia practice in this book. Whilst William Morton, Horace Wells, and
Charles Jackson were enmeshed in lawsuits over the superiority of exploration of ether and its advantage, Snow concentrated on what to do and how to do it (14).

He was the first who realized that it was necessary to use an exact mixture of anesthetic agent and air to prevent asphyxiation. According to his statements this mixture depended on temperature. He created a five point clinical scale in order to assess the depth of unconsciousness. He had dairy notes about outcomes and side-effects of each method. Snow was the first person to express that it is necessary that someone other than the surgeon should observe the patient and monitor anesthesia (19).

He introduced anesthesia as a process of preparing the mixture and delivering it to the patient. Snow monitored and compared the different effects of the different anesthetic agents.

He was looking for the best anesthetic agent and working on the mode of communication of Chloroform in the last moments of his life. He finally succeeded to use chloroform at two of the Queen Victoria's deliveries in which he himself played a role as an anesthetist (19).

John Snow (1813-1858 CE), the outstanding epidemiologist and anesthesiologist, published many books, papers and letters on a wide range of subjects in the field of medicine. He was a memorable scientist for his significant role in improving scientific basis of anesthesia and promoting the epidemiology and working on prevention of cholera. Innovation and creativity were his singular and unique features in his researches.

\section{Acknowledgement}

The authors would like to express their deepest gratitude to Library \& Archives Service, London School of Hygiene \& Tropical Medicine for the image of Dr. John Snow and his map. 


\section{References}

1. Leaman A. John Snow MD--his early days. Anaesthesia. 1984; 39(8):803-5.

2. Snow SJ. John Snow MD (1813-1858). Part II: becoming a doctor - his medical training and early years of practice. J Med Biogr. 2000; 8(2):71-7.

3. Maltby JR, Bamforth BJ. The Wood Library-Museum's 1858 edition of John Snow's On chloroform and other anaesthetics. Anesth Analg. 1990; 71(3):288-94.

4. Hill AB. The environment and disease: association or causation? 1965. J R Soc Med. 2015; 108(1):32-7. doi: $10.1177 / 0141076814562718$.

5. Paneth N. Assessing the contributions of John Snow to epidemiology: 150 years after removal of the broad street pumphandle. Epidemiology. 2004; 15(5):514-6.

6. Robens. The fourteenth John Snow Memorial Lecture. Anaesthesia. 1973; 28(2):170-5.

7. Cameron D, Jones IG. John Snow, the broad street pump and modern epidemiology. Int J Epidemiol. 1983; 12(4):393-6.

8. Fine P, Victora CG, Rothman KJ, Moore PS, Chang Y, Curtis V, Heymann DL, Slutkin G, May RM, Patel V, Roberts I, Wortley R, Torgerson C, Deaton A. John Snow's legacy: epidemiology without borders. Lancet. 2013; 381(9874):130211. doi: 10.1016/S0140-6736(13)60771-0.

9. Ashbolt NJ. Microbial contamination of drinking water and disease outcomes in developing regions. Toxicology. 2004; 198(1-3):229-38.

10. Vandenbroucke JP. Changing images of John Snow in the history of epidemiology. Soz Praventivmed. 2001; 46(5):288-93.

11. Colwell RR. Global climate and infectious disease: the cholera paradigm. Science. 1996; 274(5295):2025-31.

12. Newsom SW. Pioneers in infection control: John Snow, Henry Whitehead, the Broad Street pump, and the beginnings ofgeographical epidemiology. J Hosp Infect. 2006; 64(3):210-6. Epub 2006 Aug 7.

13. McLeod KS. Our sense of Snow: the myth of John Snow in medical geography. Soc Sci Med. 2000; 50(7-8):923-35.

14. Paneth N, Fine P. The singular science of John Snow. Lancet. 2013; 381(9874):1267-8.

15. Webb JC, Mergler D, Parkes MW, Saint-Charles J, Spiegel J, Waltner-Toews D, Yassi A, Woollard RF. Tools for thoughtful action: the role of ecosystem approaches to health in enhancing public health. Can J Public Health. 2010; 101(6):439-41.

16. JNewsom SW. Pioneers in infection control: John Snow, Henry Whitehead, the Broad Street pump, and the beginnings ofgeographical epidemiology. Hosp Infect. 2006; 64(3):210-6.

17. MACKINTOSH JM. Snow, the man and his times. Proc R Soc Med. 1955; 48(12):1004-7

18. BROWN PE. ANOTHER LOOK AT JOHN SNOW. Anesth Analg. 1964; 43:646-54.

19. Caton D. John Snow's practice of obstetric anesthesia. Anesthesiology. 2000; 92(1):247-52. 